\title{
Carotenoid composition and content in products of sea buckthorn and peach as determined by high-performance liquid chromatography
}

\author{
Daood, H. G. ${ }^{1}$, Solymos, K. ${ }^{1}$, Bánáti, D. ${ }^{1}$, Berta, Z. ${ }^{2}$, Nyéki, J. ${ }^{3}$ \& Szabó, Z. ${ }^{3}$ \\ ${ }^{1}$ Central Food research Institute, Herman Ottó u. 15, 1022 Budapest, Hungary (h.daood@cfri.hu) \\ ${ }^{2}$ Bio-Drug-Berta Kft, Vörösmarty u. 113. 6300 Kalocsa, Hungary \\ ${ }^{3}$ University of Debrecen Centre for Agricultural and Applied Economic Sciences, \\ H-4032 Debrecen, Böszörményi út 138., Hungary
}

\begin{abstract}
Summary: A study was conducted to analyse the carotenoids by high-performance liquid chromatography (HPLC) using reversed-phase cross linked end-capping and to study the pigment content and composition in sea buckthorn products as well as in freshly harvested fruits from peach thees grown under organic and integrated farming conditions. It was found that carotenoids in fruits of both crops occur mainly esterified with fatty acids in form of mono- and di-esters. The major carotenoids were esters of zeaxanthin, lutein, $\beta$-cryptoxanthin and $\beta$ carotene. The major carotenoids showed different response to processing of sea buckthorn being highly sensitive to thermal treatments such as blanching, cooking and drying. Significant differences were found between peach varieties in their carotenoid content, whereas the impact of organic farming on carotenoids formation was found to be variety-dependent. Two of the three varieties examined in this work, when cultivated under organic farming conditions contained lower carotenoid level as compared to that found in the fruits of the same varieties but produced in integrated farms.
\end{abstract}

Keywords: sea buckthorn, peach, carotenoids, liquid chromatography, progressing, organic farming

\section{Introduction}

Fruits of sea buckthorn and peach are among those having special importance from nutritional therapeutic points of view. Such fruits have considerably high content of bioactive compounds beside carbohydrates, proteins, lipids, amino acids and vitamins (Geetha et al., 2002; Guliyev et al., 2004). Carotenoids, as natural colorants and bioactive nutrients, have received an increasing interest during the last decades. The reactive oxygen species-scavenging activity of carotenoids and other natural antioxidants has been found to be associated with reduced risk of serious diseases including cancer (Keleman et al., 2006; Larsson et al., 2010), cardiovascular disease (Arab and Steck, 2000) and agerelated degeneration and disorder caused by the low concentration of macular pigment (Bone et al., 2000; Mozaffariech et al., 2003).

At post-harvest of plant crops, particularly during processing, carotenoids undergo some chemical alteration, such as isomerisation and oxidation on their molecules (Niizu and Rodriguez-Amaya, 2005). Such a chemical alteration can change, to a considerable extent, their chemical and biological properties (Granado et al., 1992; Molnár, 2009). Under certain biological conditions all-trans to cis geometrical isomerisation occur not only in processed foods but also in human serum (Pérez-Gálvez and MinguezMosquera, 2005).
The diversity of carotenoid extract from some plant products is due to the formation of a large number of oxygencontaining xanthophylls, which occur esterified with fatty acids in form of mono-and di-esters (Biacs et al., 1989; Biacs and Daood 1994; Minquez-Mosquera and Hornero-Méndez, 1994; Pérez Gálvez et al., 1999). Fatty acid esters of carotenoids differ substantially in their chemical and chromatographic properties from that of free ones. Depending on fatty acid moiety antioxidant activity of carotenoid esters may or may not be altered (Mustafuji et al., 1998; Pérez-Gálvez and Minguez-Mosquera, 2002; Subagio and Morita, 2001 and 2003). To simplify the carotenoid extract, the pigment is often subjected to alkaline hydrolysis (saponification) to hydrolyse fatty acid esters and to dissociate their bounds with the macromolecules such as proteins (Ágos et.al., 2007; Meléndez-Martínez et al., 2007; De Faria et al., 2009). However, conventional gradient elution is recommended to separate the individuals of carotenoid pigment even in saponified extracts.

The objective of the present work was to study the carotenoids composition of sea buckthorn, by applying recent liquid chromatographic (HPLC) method with the use of adsorbent having cross-linked C18 end-capping and gradient elution of water in acetone. Also, the comparison with the carotenoid composition of peach fruit and studying the changes in carotenoid content and composition of sea buckthorn as a function of processing was aimed. 


\section{Materials and methods}

\section{Materials}

Fresh, frozen and processed sea buckthorn products were from Bio-Drug-Berta Ltd. (Fajsz, Hungary), while the fruits of peach were obtained from the experimental fields of the University of Debrecen (Debrecen, Hungary). Standard materials of all-trans $\beta$-carotene, lutein, Zeaxanthin, and lycopene were purchased from Sigma-Aldricht (Budapest, Hungary). $\beta$-cryptoxanthin and was obtained with the courtesy of the Institute of Bio- and Medical Chemistry of the University of Péch (Hungary). HPLC- and analytical grade organic solvents were from Merck (Darmstat, Germany).A cross-linked Nucleodur ISIS C-18 UPLC column was from Machery-Nagel $\mathrm{GmbH} \& \mathrm{Co}$. (Düren, Germany).

The freshly harvested fruits of both crops were cut into small pieces by a stainless steel knife and stored at $-20^{\circ} \mathrm{C}$ in a vacuumed nylon sacs when not immediately analysed

\section{Methods}

\section{Extraction of carotenoids}

Five grams of fresh or processed products were crushed in a crucible mortar in the presence of $1 \mathrm{~g}$ of quartz sand and $0,5 \mathrm{~g}$ ascorbic acid. The extraction procedure started with macerating with methanol to bind the water. The mixture was left to stand for few minutes and the supernatant was carefully decanted into a $100 \mathrm{ml}$ Erlenmeyer flask. The residues in the mortar were further crushed with gradual addition of $50 \mathrm{ml}$ of 1,2-dichloroethan-methanol (6:1) and the mixture was transferred to the flask containing methanol fraction. The liquid-liquid phase separation of carotenoids was initiated by adding few drops of water and mechanical shaking for $15 \mathrm{~min}$ at room temperature according to a previously described procedure (Biacs and Daood, 1994). The lower phase containing carotenoids was separated in a separating funnel, dehydrated on anhydrous $\mathrm{Na}_{2} \mathrm{SO}_{4}$ and evaporated under vacuum at maximum $40{ }^{\circ} \mathrm{C}$. The residues were re-dissolved in pure acetone and passed through a 0,45 $\mu \mathrm{m}$ PTFE syringe filter aid before injection onto HPLC column.

To saponify the carotenoid pigment, the extracted pigment was re-dissolved in $20 \mathrm{ml}$ petroleum ether and subjected to alkaline hydrolysis with $20 \mathrm{ml}$ of $30 \% \mathrm{KOH}$ in methanol for $1 \mathrm{~h}$ at dark place. Carotenoids were then extracted with ethyl acetate, which was pooled and washed with double distilled water. The organic layer was then dried on anhydrous $\mathrm{Na}_{2} \mathrm{SO}_{4}$ and evaporated to dryness under vacuum at $40{ }^{\circ} \mathrm{C}$. The pigment was re-dissolved in HPLC grade acetone before injection.

\section{HPLC conditions and instrument}

A Waters Alliance liquid chromatographic instrument consisting of a Model 2695 Separation Module (Gradient pump, auto-sampler and column heater) and a Model 2975 Photodiode-Array Detector was used. Operation and data processing were performed by Empower software.

Separation of carotenoids was performed on Nucleodur ISIS, $3 \mu \mathrm{m}, 15 \mathrm{~cm} \times 4,6 \mathrm{~mm}$, column with gradient elution of (A) water and (B) acetone. The elution started with $20 \% \mathrm{~A}$ in $\mathrm{B}$, which changed to $10 \% \mathrm{~A}$ in $\mathrm{B}$ in 7 min then to $5 \% \mathrm{~A}$ in $\mathrm{B}$ in $5 \mathrm{~min}$ and stayed isocratic for $5 \mathrm{~min}$ and turned to $20 \%$ $\mathrm{A}$ in $\mathrm{B}$ in $3 \mathrm{~min}$. The flow rate was $0.7 \mathrm{ml} \mathrm{min}^{-1}$. Detection of carotenoids was performed between 200 and $700 \mathrm{~nm}$. For quantification, each compound was detected at the maximum wavelength of its light absorbance.

Stock solutions for lycopene, zeaxanthin and $\beta$-carotene were prepared by dissolving $1 \mathrm{mg}$ of standard materials (Sigma, St. Lo. USA) in $10 \mathrm{ml}$ of petroleum ether using brown-coloured volumetric flasks. Working solutions, between 0 and $100 \mu \mathrm{g} / \mathrm{ml}$, were prepared by dilution with HPLC acetone and injected onto the HPLC system. The recorded peak areas of standard solutions was Plotted versus concentrations to get the calibration curve using Microsoft xls 2007 program

Identification: The peaks were identified by comparing their spectral characteristics and retention times with those of standard materials and with literature data when available (Bauernfeind, 1981). The identification of any individual of carotenoids basing on only retention and spectral characteristics is considered tentative unless confirmed by standard or structural elucidation means such as mass spectroscopy (MS) or magnetic nuclear resonance (NMR).

\section{Statistical analysis}

Standard deviation and One-way analysis of variance (ANOVA) (Minitab statistical program) was performed to statistically analyse the differences between the samples.

\section{Results and discussion}

\section{Carotenoid composition}

HPLC profiles carotenoids from hydrolysed and unhydrolysed extract of sea buckthorn are shown in Figure1 and 2. In such a crop, carotenoids occur mainly esterified with fatty acids in form of mono- and di-esters. Zeaxanthin was found dominant carotenoid followed by $\beta$-cryptoxanthin, $\beta$-carotene and mutatoxanthin. The fatty acid esters of the main xanthophylls were dominant with a ratio of esterified/unesterified was over 9/1. In general these results agree with the results of HPLC analysis of carotenoids from sea buckthorn fruits, which has been reported by Guliyev et.al., (2004). The authors reviewed that fresh fruits distribute mainly carotenes and palmitat esters of zeaxanthin and $\beta$-cryptoxanthin.

As minor individuals, $\gamma-\gamma$ carotene, lycopene, rubinaxanthin and some of their epoxides and cis isomers could also be detected and tentatively identified. The 


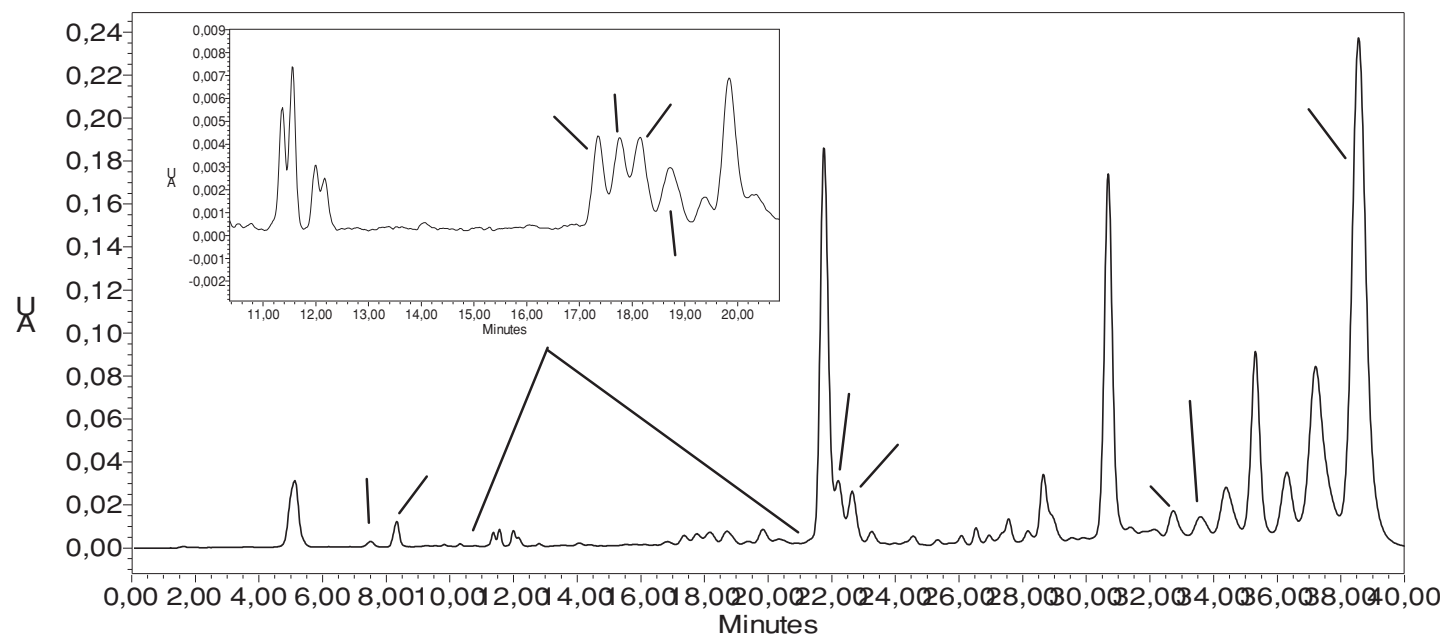

Fig.1: HPLC profile of carotenoids from un-hydrolysed extract of sea buckthorn. 1: zeaxanthin, 2,3: cis-zeaxanthin, 6: $\beta$-cryptoxanthin, 7: lycopene epoxide, 8: $\gamma$ - $\gamma$-carotene, 9: lycopene, 10: cis-lycopene, 11: rubixanthin,12: $\beta$-carotene, 13: 9Z- $\beta$-carotene, 14: 13Z- $\beta$-carotene, $15,16: \beta$-cryptox. ME, 17, 18, 19, 21 : mutatoxanthin. DE, 20,23: zeaxanthinDE, 22: lutein DE

performance of the applied HPLC method was high enough tm make it capable to separate not only the different esters of the different xanthophylls, but also the 9- and 13- cis isomers of the major carotenes, xanthophylls and their fatty acid esters. Since cis isomers were detected in both hydrolysed and un-hydrolysed sea buckthorn extracts, it can be concluded that biochemical pathway of cis-trans isomerisation is activated, to some extent, during ripening and post-harvest handling of such a product.

In case of peach (Fig. 3), the pigment consists of mainly $\beta$-carotene and fatty acid esters or free forms of violaxanthin, lutein, zeaxanthin and cryptoxanthin. The ratio of esterified/ unesterified carotenoids was found to be around 2.5/1, which is well below the value found in sea buckthorn as mentioned before. The difference in degree of esterification of xanthophylls with fatty acids my affect colour intensity and stability of the pigment in different fresh or processed products of such crops since the fatty acid esters of xanthophylls have been found to be more stable than the free forms towards oxidative degradation (Biacs et al., 1992; Subagio and Morita, 2003).

It is worthy to mention that most of carotenoids of sea buckthorn and peach are biologically active and may attribute to the therapeutic and immune-modulating properties of such fruit, which has been confirmed by some studies (Guliyev et al., 2004). Also, it is to be mentioned that occurrence of lutein, zeaxanthin and $\beta$-cryptoxanthin as fatty acid esters in fruits or vegetables does not reduce the biologically activity of such carotenoids because mono-and di-esters can be hydrolysed by active de-esterase enzymes that function in the human intestine (Pérez-Gálvez and Minguez-Mosquera, 2005), and moreover, antioxidant activity of carotenoid esters containing saturated fatty acids is almost the same of the correspondent free forms (Matsufuji et al., 1998; Subagio and Morita, 2001).

\section{Efeects of technology}

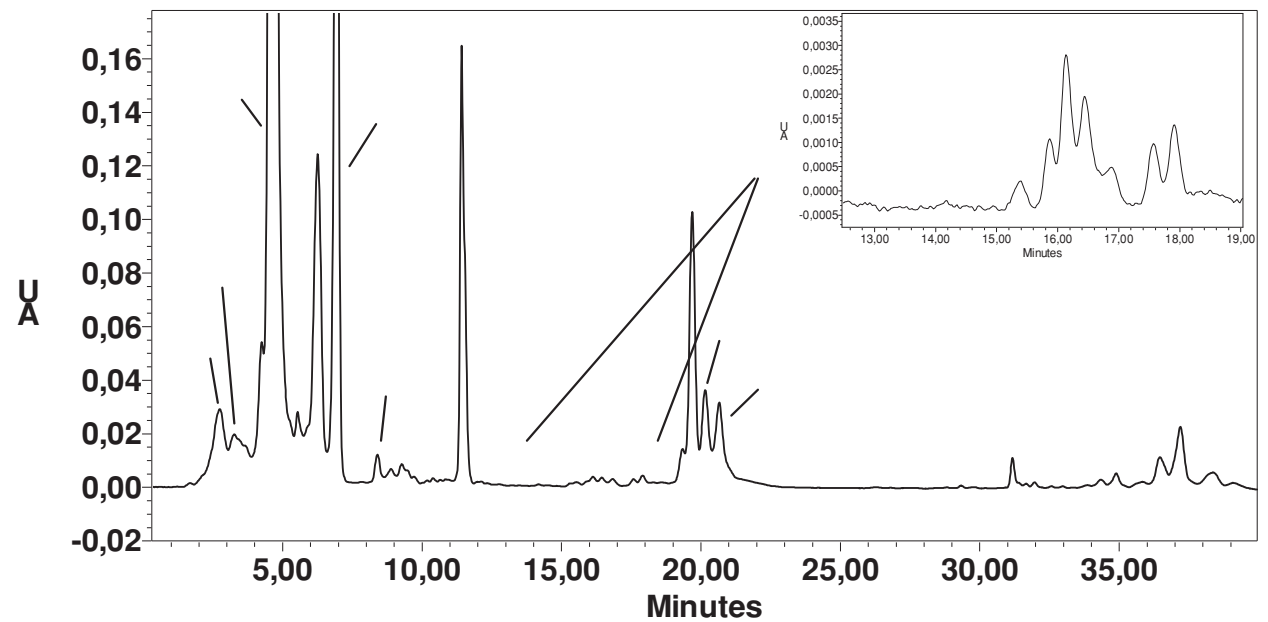

Fig 2: HPLC profile of carotenoids from hydrolysed extract of sea buckthorn. 1: mutatoxanthin, 2: lutein, 3: zeaxanthin, 4, 5: cis-zeaxanthin, 6: $\beta$-cryptoxan. epoxide, 7: $\beta$-cryptoxanthin, 8: lycopene-epoxide, 9: $\gamma-\gamma$-carotene, 10: lycopene, cis-lycopene, 12 , 13: rubixanthin, 14: $\beta$-carotene, 15: 9Z- $\beta$-carotene, 16:13Z$\beta$-carotene 


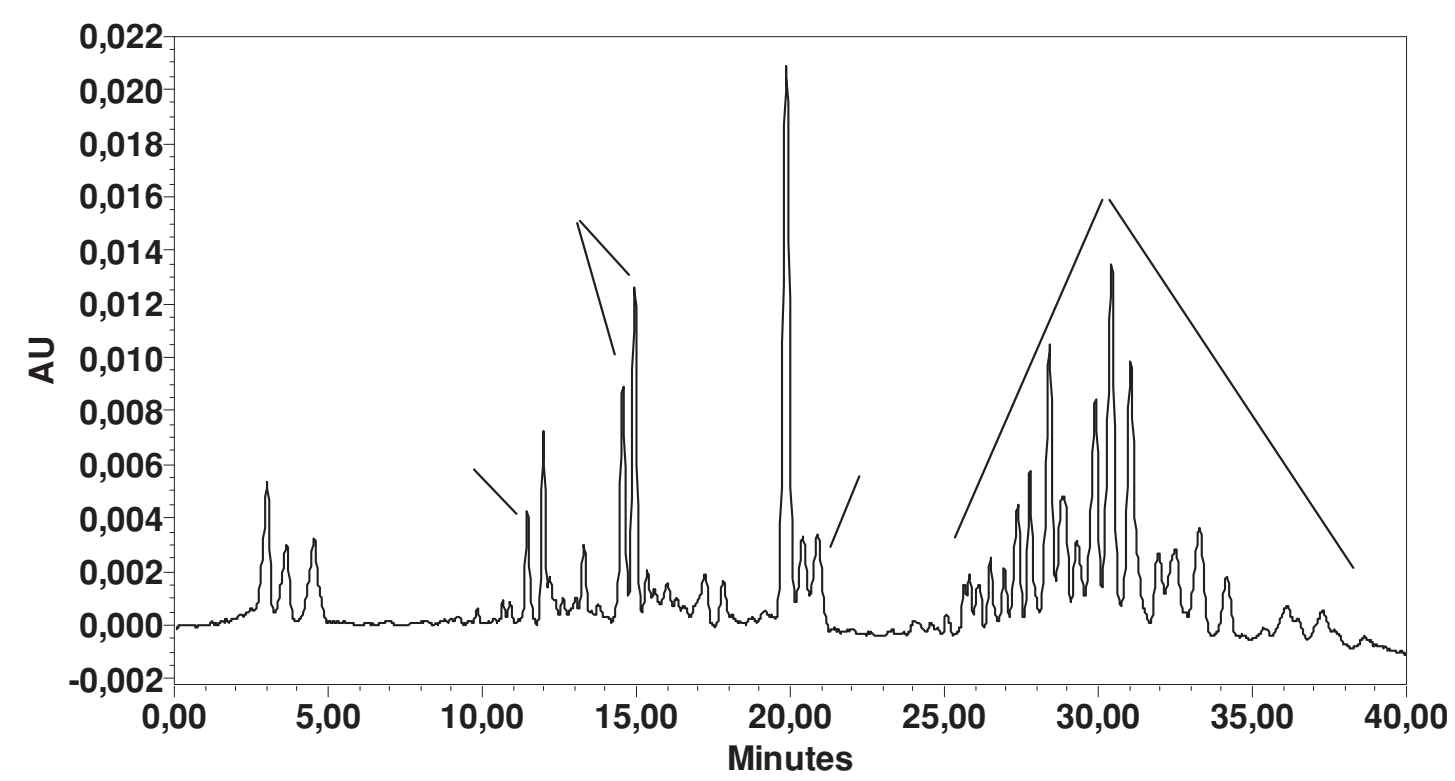

Fig 3: HPLC profile of carotenoids from ripe peach fruit. 1: lutein epoxide 2: zeaxananthin, 3: $\beta$-cryptoxanthin, 4:Zeaxanthin monoester, 5: Lutein monoesters, $\beta$-carotene, 7: 9Z- $\beta$-carotene $+\zeta$-carotene, 8: 13Z- $\beta$-carotene, 9: xanthophyll diesters

\section{Processing of sea buckthorn}

Sea buckthorn is often harvested at biological ripeness stage when the fruits turn yellow-orange in colour. Because of being climacteric fruit, biochemical processes including carotenoid biosynthesis are expected to continue in biological ripeness stage, which should proceed towards technological ripeness or over-ripeness. At the later stage flavour, colour and taste of the fruits should approach the desired level for both fresh consumption and processing.

Table 1 shows the carotenoid content of freshly harvested fruits and processed products of sea buckthorn produced in the previous seasons (2009) in addition to one product (nectar) stored for 5 years in dark and cool store. The HPLC analysis of carotenoid composition of sea buckthorn extracts showed that content, in dry matter, of free zeaxanthin is significantly lower and that of $\beta$-carotene and all of the di-esters is higher in fresh fruits than their content found in the dry matter of the frozen fruits and nectar produced at the same season. This is most likely due to probable variation in ripening stage of fresh fruits taken for analyses and fruits subjected to different processing. It is to be mentioned that due to the limited capacity of the laboratories it was not possible to immediately analyse the fresh fruits, which were kept at cool store at $5-10{ }^{\circ} \mathrm{C}$ for 3 days after harvest. It seemed that at such conditions fruits preceded in ripening towards full or even over-ripeness, at which carotenoid biosynthesis and esterification with fatty acids can be accomplished. In pilot plants and factories such ripeness cannot be ensured with great batches of this crop to be processed.

Among products of 2009, the lowest level of total and some individuals of carotenoid pigment of sea buckthorn fruits was found in freeze-stored samples, in which the total carotenoid content was significantly lower $(p=0.01)$ by approximately $34 \%$ as related to the content in fresh fruits or

\begin{tabular}{|c|c|c|c|c|c|c|}
\hline \multirow[t]{2}{*}{ Karotinoidok } & \multicolumn{6}{|c|}{ Concentration ug/100g dry matter } \\
\hline & Fresh & Frozen & Nectar & Nectar 2004 & Jam & $\begin{array}{l}\text { Ground } \\
\text { product }\end{array}$ \\
\hline Zeaxanthin & $292 \pm$ & $638 \pm$ & $599 \pm$ & $651 \pm$ & $118 \pm$ & $607 \pm$ \\
\hline 9-Z zeaxantin & $10 \pm$ & $\operatorname{tr}$ & $135 \pm$ & $148 \pm$ & $6 \pm$ & $\operatorname{tr}$ \\
\hline 13-Z zeaxantin & $19 \pm$ & $\operatorname{tr}$ & $161 \pm$ & $67 \pm$ & $12 \pm$ & $35 \pm$ \\
\hline$\beta$-cryptoxanthin & $17 \pm$ & $49 \pm$ & $71 \pm$ & $33 \pm$ & $3 \pm$ & $4 \pm$ \\
\hline Mutatoxantin ME & $60 \pm$ & $134 \pm$ & $80 \pm$ & $71 \pm$ & $7 \pm$ & ny \\
\hline Rubixanthin & $10 \pm$ & $39 \pm$ & $65 \pm$ & $48 \pm$ & $10 \pm$ & $5 \pm$ \\
\hline Lycopene & $15 \pm$ & $86 \pm$ & $123 \pm$ & $18 \pm$ & $8 \pm$ & $\operatorname{tr}$ \\
\hline$\gamma \gamma$-carotene & $67 \pm$ & $407 \pm$ & $411 \pm$ & $106 \pm$ & $11 \pm$ & $\operatorname{tr}$ \\
\hline$\beta$-carotene & $1315 \pm$ & $2561 \pm$ & $2071 \pm$ & $476 \pm$ & $206 \pm$ & $566 \pm$ \\
\hline 9-Z $\beta$-carotene & $55 \pm$ & $99 \pm$ & $134 \pm$ & $60 \pm$ & $20 \pm$ & $40 \pm 1$ \\
\hline 13-Z $\beta$-carotene & $43 \pm$ & $206 \pm$ & $501 \pm$ & $118 \pm$ & $12 \pm$ & $25 \pm$ \\
\hline Mutatoxanthin DE & $517 \pm$ & $530 \pm$ & $591 \pm$ & $454 \pm$ & $19 \pm$ & $30 \pm$ \\
\hline$\beta$-cryptoxanthin ME & $1265 \pm$ & $786 \pm$ & $955 \pm$ & $478 \pm$ & $69 \pm$ & $138 \pm$ \\
\hline Zeaxanthin DE & $16125 \pm$ & $5485 \pm$ & $11028 \pm$ & $6279 \pm$ & $1184 \pm$ & $938 \pm$ \\
\hline Cisz-zeaxanthin DE & $168 \pm$ & $112 \pm$ & $2199 \pm$ & $1873 \pm$ & $127 \pm$ & $\operatorname{tr}$ \\
\hline Lutein DE & $1630 \pm$ & $422 \pm$ & $668 \pm$ & $548 \pm$ & $105 \pm$ & $108 \pm$ \\
\hline Total carotenoid & $17070 \pm 2$ & $11444 \pm$ & $17860 \pm$ & $13344 \pm$ & $1834 \pm$ & $5058 \pm$ \\
\hline
\end{tabular}


nectar. The impact of processing treatments as well as ripening stage of fruits may stand behind the reason for the low level of carotenoids in freeze-stored product.

Cold-break extraction followed by passing through a sieve and heat treatment at $100{ }^{\circ} \mathrm{C}$ for $10 \mathrm{~min}$ to produce the nectar was found to have no significant effect on the total carotenoid content although substantial variation was noticed in the proportion of the individuals of carotenoid pigment as mentioned before. In case of nectar stored for 5 years at cool store, the content of most of carotenoids, except that of zeaxanthin, was significantly lower $(p=0.05)$ than that determined in nectar samples produced in 2009. Since nectars were stored in a glass jars without removal of molecular oxygen, the loss of carotenoids was expected to be taken place as a function of oxidative deterioration.

Great destruction of carotenoids was also expected as a function of drastic heat treatments applied in the preparation of jam, which contained about $10 \%$ of the total carotenoids found in fresh fruits. In addition, dilution with added sugar and pectin should be considered as an additional reason for the high loss of carotenoids in jam samples from sea buckthorn.

The carotenoid composition and content of ground product of sea buckthorn is different from that of fresh fruits, nectars and jam because this product consists of branches, leaves and fruits of the crop. The purpose of preparation of such a mixture was to offer a product with increased medicinal effect exploiting the high biological and therapeutic properties of leave and branch extracts (Geetha et al., 2002; Gyliyev and Yildrim, 2004). The product is prepared by washing and thermal drying followed by course grinding of fruits, leaves and branches of sea buckthorn. Although addition of leaves and branches had a dilution effect on the carotenoids of the fruits it caused the concentration of Zeaxanthin to be at close level to that determined in frozen fruits or nectars and level of $\beta$-carotenes to be $20-25 \%$ of that recorded for the best nectar despite high degradation usually takes place on carotenoids as a result of thermal drying.

As a function of thermal treatments either in blanching before freezing or sterilization after cold break extraction in nectar processing, marked increase was recorded for cis-forms of both carotenes and xanthophyll esters. It has been repeatedly mentioned in literature that carotenoid degradation starts with all-trans to cis isomerisation, which is usually initiated by heat treatments in food processing (Shierle et al., 1997; Nguyen and Schwartz, 1998; Faulks and Southon, 2005; Fratianni et al., 2010). However, in case of nectar produced in 2004 and stored in a cool store for 5 years, the content of $\beta$-carotene and its cis- isomer was lower than that of the other products revealing the sensitivity of these compounds to oxidative stress during un-controlled storage of such a product.

\section{Cultivation technology and variety of peach}

In a project investigating the effect of organic and integrated farming on the carotenoid content of different varieties, samples of ripe fruits were taken for analysis in two seasons (2008 and 2009). As shown in Table 2 the different varieties differ substantially in their carotenoid content, but not in the pigment composition. All the varieties listed in the table are of yellow-coloured pulp. Those varieties of white or faint green pulp were excluded from the analysis of carotenoids. The range estimated for the total carotenoids content was $0.42-0.98 \mathrm{mg}$ per $100 \mathrm{~g}$ edible portion, which is close to the average found for peach varieties of British Columbia tree, and lower than the 1.2-5.4 mg/100 g recorded for Australian canning clingstone varieties (Bauernfeind, 1981).

In the two different seasons, the impact of organic farming on carotenoid content was found to be variety-dependent. With Early Redhaven and Panada varieties carotenoid content of peach from organic farming was significantly lower $(p=0.05)$ than that of fruits from integrated farms, while opposite results were obtained with Cresthaven, which contained significantly higher carotenoid level $(p=0.01)$ when
Table 2: Content of carotenoids in fruits of different peach varieties cultivated with organic and conventional farming conditions

\begin{tabular}{|l|c|c|c|c|c|c|c|}
\hline \multirow{2}{*}{ Component } & \multicolumn{7}{|c|}{ Concentration ug/100g } \\
\cline { 2 - 9 } & $\begin{array}{c}\text { Early RH } \\
\text { Integ. }\end{array}$ & $\begin{array}{c}\text { Early RH } \\
\text { Bio }\end{array}$ & $\begin{array}{c}\text { Padana } \\
\text { Integ. }\end{array}$ & $\begin{array}{c}\text { Padana } \\
\text { Bio }\end{array}$ & $\begin{array}{c}\text { CrH } \\
\text { Integ. }\end{array}$ & $\begin{array}{c}\text { CrH } \\
\text { Bio }\end{array}$ & $\begin{array}{c}\text { Sweet } \\
\text { Lady } \\
\text { Integ. }\end{array}$ \\
\hline Lutein-epoxide & 11,4 & 9,1 & 34,4 & 20,1 & 10,4 & 82,2 & 200,6 \\
\hline Zeaxanthin & 21,1 & 16,2 & 23,4 & 19,0 & 18,5 & 15,2 & 14,2 \\
\hline Zeaxanthin ME & 3,1 & 2,4 & 1,8 & 0,6 & 0,4 & 0,6 & 2,1 \\
\hline B-cryptoxanthin & 24,6 & 18,6 & 35,1 & 13,5 & 14,9 & 36,4 & 48,0 \\
\hline Lutein ME & 25,3 & 22,0 & 72,1 & 19,7 & 15,4 & 18,7 & 57,6 \\
\hline B-carotene & 77,2 & 67,7 & 190,1 & 104,6 & 130,5 & 174,7 & 216,3 \\
\hline B-cryptoxanthin ME & 131,2 & 107,6 & 180,1 & 72,0 & 100,2 & 129,8 & 115,4 \\
\hline Zeaxanthin DE & 15,7 & 15,1 & 30,2 & 12,8 & 12,7 & 10,6 & 11,6 \\
\hline Lutein DE & 144,6 & 112,3 & 332,5 & 126,8 & 97,1 & 110,9 & 209,4 \\
\hline Violaxanthin DE & 71,3 & 55,6 & 88,0 & 41,0 & 47,3 & 53,6 & 77,0 \\
\hline Total & 525,5 & 426,5 & 987,6 & 430,2 & 447,5 & 632,6 & 952,2 \\
\hline
\end{tabular}

cultivated under organic farming conditions. As regards the response of the individual compounds to the type of cultivation technology, lutein epoxide and $\beta$-cryptoxanthin exhibited the higher response than that noticed with the other carotenoids that were moderately responding to the change in the cultivation conditions. 


\section{Acknowledgement}

This work was financially supported by the Hungarian Ministry of Agriculture and Rural Development and NFÜ TECH_08-A3/2-2008-0373 grant.

\section{References}

Geetha, S., Sai Ram M., Singh V., Ilavazhagan G. \& Sawhney R.C. (2002): Anti-oxidant and immunomodulatory properties of sea buckthorn (Hyppophae rhamnoides) - an in vitro study. J. Ethnopharmacology, 79: 373-378.

Guliyev V., Gul M. \& Yildirim A. (2004): Hyppophae rhamnoides L.: Chrom,autographic methods to determine chemical composition, use in traditional medicine and pharmacological effects. J. Chromatogr. B, 812: 291-307.

Keleman L.E., Cerhan J.R., Lim U., Daves S., Cozen W. \& Schenk M. (2006); Vegetables, fruits, and antioxidant-related nutrients and risk of non-hodgkin lymphoma. Am. J. Clin. Nutr., 83: 1401-1410.

Larsson S., Bergkvist L. \& Wolk A. (2010): Dietary carotenoids and risk of hormone receptor-defined breast cancer in a prospective cohort of Sweden women. Eur. J. Cancer, 46: 1079-1085.

Arab L. \& Steck S. (2000): lycopene and cardiovascular disease. Am. J. Clin. Nutr. 169, 1S-5S.

Bone R.A., Landrum J.T., Dixon Z., Chen Y. \& Llierena C.M. (2000): Lutein and zeaxanthin in the eyes, serum and diet of human subjects. Experim. Eye Res. 71: 239-245.

Mozaffariech M., Sacu S. \& Wedrich A. (2003): The role of the carotenoids, lutein and zeaxanthin, in protecting against age-related macular degeneration: a review based on controversial evidences. J. Nutr. 2: 20-28.

Niizu P.Y. \& Rodriguez-Amaya B. (2005): New data on the carotenoid composition of raw salad vegetables. J. Food Compos. Anal. 18: 739-749.

Granado F., Olmedilla B., Blanco I. \& Rojas-Hidalgo E. (1992): Carotenoid composition in raw and cooked Spanish vegetables. J. Agric. Food Chem. 40: 2135-2140.

Molnár P. (2009): Research of the (E/Z)-i isomerisation of carotenoids in Péch since the 1970s. Arch. Biochem. Biophys. 483: 156-164.

Pérez-Gálvez A. \& Mínguez-Mosquera M.I. (2005): Esterification of xanthophylls and its effect on chemical behaviour and bioavailability of carotenoids in the human. Nutr. Res. 25: 631-640.

Biacs, P.A., Daood, H.G., Pavisa, A. \& Hajdú, F. (1989): Studies on carotenoid pigments of paprika. (Capsicum annuum L. Var. Sz-20) J. Agric. Food Chem., 37: 350-353.
Biacs, P.A. \& Daood, H.G. (1994): High-performance liquid chromatography with photodiode-array detection of carotenoids and carotenoid esters in fruits and vegetables. J. Plant Phys., 143: 520-525

Bauernfeind J.Ch. (1981): Carotenoids as colorants and vitamin A precursors. Academic Press, New York

De Faria, A.F., Hasegawa, P.N., Chagas, E.A., Pio, R., Purgatto, E. \& Mercadanta, A.Z. (2009): Cultivar influence on carotenoid composition of loquats from Brazil. Journal of Food Composition and Analysis, 22: 196-203.

Maléndez-martínez, A.J., Vicario, I.M. \& Heredia, F.J. (2007): Review: Analysis of carotenoids in orange juice. Journal of Food Composition and Analysis, 20: 638-649.

Nagy, V., Szabó, Z., Márk, L., Ohmacht, R. \& Deli, J. (2007): Comparative study on the carotenoid composition of the peel and the pulp of different citrus species. Innovative Food Science and Emerging Technologies, 8: 390-394.

Minquez-Mosquera, M.I. \& Mornero-Méndez, D. (1994): Changes in carotenoid esterification during the fruit ripening of capsicum annuum Cv. Bola. Journal of Food and Agricultural Chemistry, 42: 640-644.

Pérez-Gálvez A., Garrido-Fernández, J., Mínguez-Mosquera M.I., Lozano-Ruiz, M. \& Montero-de-Espinosa (1999): V. Fatty acid composition of two new pepper varieties (Capsicum annuum $\mathrm{L}$. cv. Jaranda and Jariza). Effect of drying process and nutritional aspect. Journal of American Chemists Society, 76: 205-208

Mutsufuji, H., Makamura, H., Chino, M. \& Takeda, M. (1998): Antioxidant activity of capsanthin and the fatty acid esters in paprika (Capsicum annuum). Journal of Agricultural and Food Chemistry, 46: 3468-3472.

Subagio, A. \& Morita, N. (2001): No effect of esterification with fatty acid on antioxidant activity of lutein. Food Research International, 34: 2006-2013.

Subagio, A. \& Morita, N. (2003): Prooxidant activity of lutein and its dimyristate esters in corn triglyceride. Food Chemistry, 81: 97-102.

Schierle, J., Bretzel, W., Buhler, I., Faccin, N., Hess, N., Steiner, K. \& Schuep, W. (1997): Content and isomeric ratio of lycopene in food and human plasma. Food Chemistry, 59: 459-465.

Nguyen, M.L. \& Schwartz, S.J. (1998): Lycopene staibility during processing. Proceedings of the Society for Experimental Biology and Medicine, 218 (2): 101-105.

Fratianni, A., Cinquanta \& L. Panfili, G. (2010): Degradation of carotenoids in orange juice during microwave heating. LWT-Food Science and Technology, 43: 867-871.

Faulks, R.M. \& Southon, S. (2005): Challenged to understanding and measuring carotenoid bioavailability. Biochimica Biophysica Acta, 1740, 95-100. 